\title{
Mackerel icefish Champsocephalus gunnari in the diet of upper trophic level predators at South Georgia: implications for fisheries management
}

\author{
Keith Reid*, Simeon L. Hill, Tania C. D. Diniz, Martin A. Collins \\ British Antarctic Survey, Natural Environment Research Council, High Cross, Madingley Road, Cambridge CB3 0ET, UK
}

\begin{abstract}
The mackerel icefish Champsocephalus gunnari Lönnberg is an important component of the ecosystem at South Georgia. Its diet is dominated by Antarctic krill Euphausia superba; in turn, it is also an important prey of a number of upper trophic level predators, as well as being the target of commercial fisheries. Data on the frequency and size structure of mackerel icefish in the diet of Antarctic fur seals Arctocephalus gazella and gentoo penguins Pygoscelis papua from 1991 to 2002 were used to examine trophic interactions involving this species and to evaluate the potential impact of predators on its population. Mackerel icefish occurred in 10 to $20 \%$ of scats from Antarctic fur seals and comprised $48 \%$ of the diet by mass of gentoo penguins. The contribution of mackerel icefish to the diet of predators was in inverse proportion to the contribution of Antarctic krill. The lengthfrequency distributions of mackerel icefish indicated a dominant mode at 130 to $180 \mathrm{~mm}$ total length (the 1+ age class), with apparent strong cohorts entering the population in 1993, 1996, 1999 and 2001. Extrapolation of diet data to produce a consumption estimate for the South Georgia population of Antarctic fur seals and gentoo penguins suggests that scientific trawl surveys may underestimate the standing stock of mackerel icefish by 1 order of magnitude. Changes in the South Georgia ecosystem over the past 2 decades may have increased the level of consumption of mackerel icefish by predators, providing a potential ecosystem-based explanation for the lack of a recovery to the preexploitation population size.
\end{abstract}

KEY WORDS: Antarctic fur seal · Arctocephalus gazella $\cdot$ Ecosystem interactions $\cdot$ Gentoo penguins Pygoscelis papua · Mackerel icefish · Champsocephalus gunnari · South Georgia

Resale or republication not permitted without written consent of the publisher

\section{INTRODUCTION}

Approaches to the management of commercial fisheries that address the ecological role of target species and the effects of the fishery on other components of the ecosystem, so-called 'ecosystem approaches', have gained considerable prominence in recent years (see e.g. Mangel et al. 1996, Gislason et al. 2000, Pikitch et al. 2004). Within the Antarctic region, the Commission for the Conservation of Marine Living Resources (CCAMLR) has adopted an ecosystem approach to the management of finfish and crustacean fisheries. Therefore, knowledge of the potential consequences of these fisheries on related and dependent species, in particular on upper trophic level species such as seals, penguins and albatrosses, is crucial to the successful implementation of management approaches within CCAMLR (Constable et al. 2000). The successful implementation of these management approaches requires an understanding of the trophic interactions between fished species and their natural predators. Particularly important information includes the age/size structure of prey of the fished population compared to the age/size structure selected by the predators and the spatiotemporal patterns of the fished population in relation to the predator foraging areas.

Much of CCAMLR's attention to ecosystem interactions has focused on Antarctic krill Euphausia superba 
and its predators (Croxall et al. 1997, Everson et al. 1999, Reid \& Croxall 2001); however, other species are commercially exploited in the Antarctic and these species have important interactions with higher trophic level predators. The mackerel icefish Champsocephalus gunnari Lönnberg is a good example, as it is an important component of the diet of some species of seals and penguins (Reid 1995, Reid \& Arnould 1996, Croxall et al. 1997), and is commercially exploited (Kock 1992). The mackerel icefish is a bentho-pelagic species that is found to depths of $700 \mathrm{~m}$ around the islands of the Scotia Sea as well as other subantarctic islands (Kock \& Everson 1997). The maximum annual catch at South Georgia, where the fishery was most extensive, was $128000 \mathrm{t}$ in 1983; this had fallen to $21000 \mathrm{t}$ in 1989, and the fishery was closed in 1990. The dynamics of the stock throughout this period are not well understood, and the methods used to assess the stock size have not been consistent. However, regular (but not annual) surveys have been conducted since 1987, and have provided stock-size estimates of between 17000 and $67000 \mathrm{t}$ (Everson et al. 1999). The fishery was reopened in the late 1990s under a new management regime with a highly precautionary catch limit of between 3000 and $4000 \mathrm{t} \mathrm{yr}^{-1}$ (for details see Everson et al. 1999).

The mackerel icefish has higher growth and development rates than most other fish species in the region and achieves sexually maturity at 3 yr of age (Kock \& Everson 1997). Given this relatively rapid sexual maturation it might be expected to recover from exploitation relatively quickly. However, following the cessation of large-scale fishing, the estimated standing stock has remained much lower than the historical catches. The reasons for this apparent lack of recovery are unclear; however, high interannual variability in the size of the standing stock of mackerel icefish at South Georgia has been attributed to periods of increased consumption by predators when the abundance of Antarctic krill (the main prey of these predators) is reduced (Agnew et al. 1998, Everson et al. 1999). This ecological interaction is further complicated by the fact that mackerel icefish feed on krill, and there are clear indications that icefish body condition, indicated by a mass-to-length ratio, declines during periods of reduced krill abundance (Everson \& Kock 2001).

Understanding the role of mackerel icefish in the South Georgia marine system (where it is both a krill predator and a prey species for other nominally krilldependent predators) is particularly important, because both icefish and krill are the subject of commercial fisheries in this region. Clearly it is important to elucidate the trophic interactions of mackerel icefish, krill and their common predators as part of an ecosystem-based approach to fisheries management. Of particular importance are the causes of variability in the consumption of mackerel icefish by those predators, and the extent to which this consumption may influence the size of the standing stock.

Antarctic fur seals Arctocephalus gazella and gentoo penguins Pygoscelis papua are amongst the known major predators of mackerel icefish at South Georgia (Table 1). Although both species mainly consume krill, mackerel icefish accounted for ca. $80 \%$ by mass of the fish consumed by Antarctic fur seals (Reid 1995, Reid \& Arnould 1996) and $30 \%$ of the diet of gentoo penguins (Croxall et al. 1997). Data on the diet composition of these 2 species have been

Table 1. Known predators of mackerel icefish Champsocephalus gunnari in the South Georgia ecosystem

\begin{tabular}{|c|c|c|c|}
\hline Predator & Season & Contribution to diet & Source \\
\hline \multirow[t]{2}{*}{ Antarctic fur seal Artocephalus gazella } & Winter & $\begin{array}{c}47 \% \text { fish mass, } \\
\text { fish in } 72 \% \text { of scats }\end{array}$ & Reid (1995) \\
\hline & Summer & $29 \%$ occurrence & Reid \& Arnould (1996) \\
\hline \multirow[t]{3}{*}{ Gentoo penguin Pygoscelis papua } & Summer & $27 \%$ mass & Croxall et al. (1997) \\
\hline & Winter 1987 & $52 \%$ otoliths & Williams (1990) \\
\hline & Winter 1988 & $3 \%$ otoliths & Williams (1990) \\
\hline Macaroni penguin Eupdyptes chrysolophus & Summer & $1.2 \%$ mass & Croxall et al. (1997) \\
\hline King penguin Aptenodytes patagonicus & Summer & $<1 \%$ all otoliths & Olsson \& North (1997) \\
\hline \multirow[t]{3}{*}{ Black-browed albatross Thalassarche melanophris } & Autumn 1996-2000 & $8-18 \%$ mass & Xavier et al. (2003) \\
\hline & Summer 1986 & $0 \%$ & Reid et al. (1996) \\
\hline & Summer 1994 & $11 \%$ mass & Reid et al. (1996) \\
\hline \multirow[t]{3}{*}{ Grey-headed albatross Thalassarche chrysostoma } & Autumn 1996-2000 & $1-16 \%$ mass & Xavier et al. (2003) \\
\hline & Summer 1986 & $0 \%$ & Reid et al. (1996) \\
\hline & Summer 1994 & $24 \%$ mass & Reid et al. (1996) \\
\hline South Georgia icefish Pseudochaenichthys georgianus & Summer & $18 \%$ mass & Collins (unpubl.) \\
\hline Scotia Sea icefish Chaenocephalus aceratus & Summer & $45 \%$ mass & Collins (unpubl.) \\
\hline \multirow[t]{2}{*}{ Patagonian toothfish Dissostichus eleginoides } & Winter & $0.5 \%$ frequency & Pilling et al. (2001) \\
\hline & Summer & $<1 \%$ mass & Collins (unpubl.) \\
\hline
\end{tabular}


obtained through the analysis of faecal samples (seals) and stomach contents (penguins) collected at Bird Island, South Georgia, since 1991, as part of the 'British Antarctic Survey Long-term Biological Monitoring Programme'. Otoliths recovered from stomachs or faeces can be used to indicate both the species and size, and by inference the age, composition of fishes in predator diets (Reid \& Arnould 1996). Since diet composition is expected to reflect prey availability as well as predator preference, the expectation is that data from otoliths in the diet can provide an insight into the population dynamics of mackerel icefish, especially when used in conjunction with independent estimates of abundance of other important components of the diet. For example the density of krill within the foraging range of predators breeding on Bird Island, measured using ship-based acoustics, indicates a significant positive relationship between the abundance of krill and the proportion of krill in the diet of gentoo penguins (Reid et al. 2005).

The aims of this study were to (1) use otoliths in diet samples to determine the occurrence of mackerel icefish in the diet of Antarctic fur seals and gentoo penguins at Bird Island, South Georgia, over the period 1991 to 2002, (2) determine what part of the population of mackerel icefish is consumed by these 2 species and what insight this information might provide about icefish population dynamics, and (3) consider the potential consumption of mackerel icefish by predators at South Georgia.

\section{MATERIALS AND METHODS}

Antarctic fur seals. A sample of 10 whole, fresh faecal samples (scats) were collected from the haul-out site at Bird Island at weekly intervals between midDecember and late March each year and every $2 \mathrm{wk}$ outside this period. Otoliths were retrieved from a scat by suspending it in a warm solution of $1 \%$ disinfectant and $1 \%$ detergent in a glass beaker and gently agitating it to break up the faecal material. If the scat did not break up easily it was left to soak for several hours or overnight. When the scat was fully suspended, the supernatant was decanted carefully into a sieve $(1 \mathrm{~mm}$ mesh) to separate dense prey remains from crustacean exoskeletons. More water was added and the process was repeated until no further faecal material was present in the supernatant. The relatively dense remains, such as fish otoliths and eyes, cephalopod beaks and eyes, and stones settled to the bottom of the beaker and were poured into a black tray (to allow colour contrast with the white otoliths) and inspected under a binocular microscope ( $\times 6$ magnification). Any identifiable prey remains were removed. Otoliths that were not identified and measured immediately were dried and stored for subsequent analysis.

Gentoo penguins. Diet samples from 10 birds were collected each week for $4 \mathrm{wk}$ during the crèche period in January to February. The samples were collected by stomach lavage (Wilson 1984) following the standard methods of the CCAMLR Ecosystem Monitoring Programme (CEMP) described by CCAMLR (1995). Care was taken to ensure that all loose otoliths were recovered and otoliths were removed from all intact crania.

Identification and measurement of otoliths. Sagittal otoliths were identified and measured, and the total length and mass of the fish were estimated using the relationship developed by Hill et al. (2005) for mackerel icefish and the relationships in Hecht (1987), Williams \& McEldowney (1990) and Reid (1996) for other species. Otoliths of mackerel icefish were measured as the greatest distance parallel to the sulcus acusticus to the nearest $0.1 \mathrm{~mm}$ using a binocular microscope ( $\times 6$ magnification) fitted with an eye-piece graticule. Only those otoliths that showed little or no sign of digestive erosion were measured. In order to estimate the contribution of mackerel icefish to the overall diet of gentoo penguins the initial 'wet mass' of fishes was attributed to each fish species in the diet according to the composition of the reconstructed fish diet derived from the species-specific relationships between otolith length and fish mass.

Data collection. Summer samples from Antarctic fur seals were collected annually, whereas winter sampling was conducted in 1992 and 1993 and then from 1998 onwards. Samples from gentoo penguins were collected in each summer; however, operational difficulties meant that no otolith measurements were made in 1998. Rates of occurrence are presented as a mean of the annual means with the range of annual means in parentheses in 'Results'.

\section{RESULTS}

\section{Frequency of occurrence and contribution of mackerel icefish to predator diet}

Antarctic fur seal. In summer a total of 911 mackerel icefish otoliths were collected from 1780 scats comprising $18.2 \%$ (1.6 to $44.4 \%$ ) of the total number of otoliths recovered. This species occurred in $10.3 \%(0.7$ to $22.9 \%$ ) of scats at an average of 0.53 (0.01 to 1.64) otoliths per scat (Table 2). Although there was considerable interannual variation, there was no temporal trend in either the frequency of occurrence $\left(F_{(1,10)}=\right.$ $0.08, p=0.78$ ) or the number of otoliths of mackerel icefish as a proportion of the total number of otoliths $\left(F_{(1,10)}=0.01, \mathrm{p}=0.92\right)$. In winter, a total of 4003 mack- 
Table 2. Champsocephalus gunnari. Occurrence of mackerel icefish in the diet of Antarctic fur seals at Bird Island, South Georgia during December to March 1991 to 2002. N: number of scats; F: frequency of occurrence of otoliths; n: total number of otoliths. Percent of mackerel icefish in total otolith count and average number of mackerel icefish otoliths per scat are also shown

\begin{tabular}{|c|c|c|c|c|c|c|c|}
\hline \multirow[t]{2}{*}{ Year } & \multirow[t]{2}{*}{$\mathrm{N}$} & \multicolumn{2}{|c|}{ All species } & \multicolumn{4}{|c|}{ C. gunnari } \\
\hline & & $F$ & $\mathrm{n}$ & $F$ & $\mathrm{n}$ & $\%$ & otoliths/scat \\
\hline 1991 & 130 & 37.7 & 459 & 6.9 & 22 & 4.8 & 0.17 \\
\hline 1992 & 150 & 3.3 & 12 & 0.7 & 1 & 8.3 & 0.01 \\
\hline 1993 & 140 & 69.3 & 617 & 15.7 & 167 & 27.1 & 1.19 \\
\hline 1994 & 140 & 51.4 & 723 & 22.9 & 230 & 31.8 & 1.64 \\
\hline 1995 & 150 & 25.3 & 735 & 2.0 & 12 & 1.6 & 0.08 \\
\hline 1996 & 140 & 21.4 & 335 & 6.4 & 67 & 20.0 & 0.48 \\
\hline 1997 & 140 & 42.9 & 531 & 20.0 & 83 & 15.6 & 0.59 \\
\hline 1998 & 150 & 16.7 & 194 & 10.7 & 33 & 17.0 & 0.22 \\
\hline 1999 & 150 & 33.3 & 257 & 20.7 & 114 & 44.4 & 0.76 \\
\hline 2000 & 150 & 24.0 & 488 & 11.3 & 122 & 25.0 & 0.81 \\
\hline 2001 & 170 & 20.0 & 331 & 4.1 & 50 & 15.1 & 0.29 \\
\hline 2002 & 170 & 14.7 & 136 & 2.4 & 10 & 7.4 & 0.06 \\
\hline
\end{tabular}

Table 3. Champsocephalus gunnari. Occurrence of mackerel icefish in the diet of Antarctic fur seals at Bird Island, South Georgia during April to November 1992, 1993 and 1996 to 2002. Further details as in Table 2

\begin{tabular}{|c|c|c|c|c|c|c|c|}
\hline \multirow[t]{2}{*}{ Year } & \multirow[t]{2}{*}{$\mathrm{N}$} & \multicolumn{2}{|c|}{ All species } & \multicolumn{4}{|c|}{ - C. gunnari } \\
\hline & & $F$ & $\mathrm{n}$ & $F$ & $\mathrm{n}$ & $\%$ & otoliths/scat \\
\hline 1992 & 179 & 59.2 & 2011 & 41.9 & 660 & 32.8 & 3.69 \\
\hline 1993 & 197 & 62.4 & 2080 & 42.6 & 1521 & 73.1 & 7.72 \\
\hline 1996 & 110 & 24.5 & 229 & 12.7 & 98 & 42.8 & 0.89 \\
\hline 1997 & 160 & 51.3 & 163 & 12.5 & 138 & 84.7 & 0.86 \\
\hline 1998 & 70 & 27.1 & 544 & 15.7 & 146 & 26.8 & 2.09 \\
\hline 1999 & 110 & 51.8 & 915 & 32.7 & 670 & 73.2 & 6.09 \\
\hline 2000 & 230 & 20.9 & 439 & 11.7 & 204 & 46.5 & 0.89 \\
\hline 2001 & 200 & 29.0 & 432 & 20.5 & 187 & 43.3 & 0.94 \\
\hline 2002 & 140 & 37.1 & 536 & 29.3 & 379 & 70.7 & 2.71 \\
\hline
\end{tabular}

erel icefish otoliths were recovered from 1396 scats and contributed 54.9\% (26.8 to $84.7 \%$ ) to the total number of otoliths. Mackerel icefish otoliths occurred in $24.4 \%$ (11.7 to $42.6 \%$ ) of scats at a mean rate of 2.9 (0.9 to 7.7) otoliths per scat (Table 3).

Gentoo penguin. A total of 5476 mackerel icefish otoliths were collected from 462 diet samples. This species occurred in $56.6 \%$ (24.3 to $100.0 \%$ ) of samples and comprised $76.8 \%$ (38.7 to 100.0 ) of all otoliths collected (Table 4). Mackerel icefish contributed $47.9 \%$ (6.7 to $81.1 \%$ ) of the overall diet by mass (Fig. 1) and there was a significant correlation between the proportion by mass of fish (of all species) and that of mackerel icefish in the diet $(r=0.96, p<$ 0.01). While there was a significant increase in the proportion of samples containing mackerel icefish over the period of the study $\left(F_{(1,10)}=9.68, \mathrm{p}<\right.$ $0.01)$, there was no such increase in the contribution made by mackerel icefish to the diet by mass $\left(F_{(1,10)}=\right.$ $0.00, \mathrm{p}=0.95)$. There was, however, a very strong negative correlation between the proportion by mass of krill and mackerel icefish in the diet ( $\mathrm{r}=-0.96, \mathrm{p}=0.001)$. Krill and mackerel icefish accounted for $>90 \%$ of the diet, by mass, in most years (Fig. 2).
Table 4. Champsocephalus gunnari. Occurrence of mackerel icefish in the diet of gentoo penguins at Bird Island, South Georgia during January to February 1991 to 2002. N: number of samples; $F$ : frequency of occurrence of otoliths; n: total numbers of otoliths; \%: percent mackerel icefish otoliths in total otolith count; nd: no data

\begin{tabular}{|cccccccc|}
\hline \multirow{2}{*}{ Year } & \multirow{2}{*}{$\mathrm{N}$} & \multicolumn{3}{c}{ All species } & \multicolumn{3}{c|}{ C. gunnari } \\
& & $F$ & $\mathrm{n}$ & $\mathrm{F}$ & $\mathrm{n}$ & $\%$ \\
\hline 1991 & 37 & 29.7 & 74 & 24.3 & 71 & 95.9 \\
1992 & 40 & 62.5 & 315 & 55.0 & 128 & 40.6 \\
1993 & 40 & 25.0 & 232 & 20.0 & 208 & 89.7 \\
1994 & 26 & 46.2 & 71 & 38.5 & 62 & 87.3 \\
1995 & 40 & 65.0 & 240 & 55.0 & 222 & 92.5 \\
1996 & 40 & 77.5 & 375 & 50.0 & 145 & 38.7 \\
1997 & 42 & 85.7 & 2111 & 81.0 & 1693 & 80.2 \\
1998 & nd & nd & nd & nd & nd & nd \\
1999 & 40 & 52.5 & 388 & 52.5 & 388 & 100.0 \\
2000 & 40 & 80.0 & 600 & 65.0 & 428 & 71.3 \\
2001 & 39 & 71.8 & 1741 & 71.8 & 1413 & 81.2 \\
2002 & 38 & 73.7 & 838 & 68.4 & 605 & 72.2 \\
& & & & & & & \\
\hline
\end{tabular}

\section{Length-frequency distribution of mackerel icefish in predator prey}

Overall, the length-frequency distributions were dominated by modes at 130 to $180 \mathrm{~mm}$ and 200 to $260 \mathrm{~mm}$, with relatively few fish $>300 \mathrm{~mm}$ (Fig. 3). The length-frequency distribution in the diet of Antarctic fur seals during summer showed the greatest degree of variability, primarily arising from the differences in the relative contribution of these 2 dominant size modes. From the time-series of length-frequency distributions, particularly for Antarctic fur seals in summer, it is possible to track the progression of dominant cohorts through the population in 2 successive years, with strong year classes apparently entering the population in 1993, 1996, 1999 and 2001. In the winter diet of Antarctic fur seals, the dominance of the 130 to $180 \mathrm{~mm}$ mode was generally more consistent than during the summer. However, in the winter of 1999 there 
was very little evidence of a cohort of this size; this cohort was also absent from the diet of seals in the following summer (2000).

In the diet of gentoo penguins, the 130 to $180 \mathrm{~mm}$ mode dominated in most years, with the exception of 2000; otoliths from this size class represented between 4.7 and $97.2 \%$ of all mackerel icefish otoliths found in gentoo penguin stomachs. Compared to fur seals there was a much more discrete separation of the modes in the length-frequency distribution for gentoo penguins. This is likely to be a consequence of the relatively discrete temporal scale of sampling ( 4 wk each summer) for gentoo penguins, compared to the much longer time scale $(4 \mathrm{mo})$ for Antarctic fur seals during which time growth of the fish would tend to produce less discrete modal sizes.

\section{DISCUSSION}

\section{Occurrence of mackerel icefish in predator diet}

The analysis of the diet of gentoo penguins indicates that they feed almost exclusively on Antarctic krill and mackerel icefish. In the case of Antarctic fur seals it appears that mackerel icefish make up a smaller part of diet but is nevertheless an important component, occurring in $10 \%$ of samples in summer and $24 \%$ in winter. There was considerable interannual variation in the level of consumption of mackerel icefish by both species. In particular the frequency of occurrence and number of otoliths per sample in the diet of Antarctic fur seals during the period from winter 1992 to summer 1994 were almost double that recorded during the rest of the time-series. For gentoo penguins, the contribution of mackerel icefish to the diet by mass was greatest in 1994 and 1991, both years of low krill availability, but it was also relatively high in 1997, 1999 and 2001, when there were no independent indications of unusually low krill abundance (Reid et al. 2005).

It has been suggested that mackerel icefish predators may exhibit abrupt switching between prey types in years of low krill availability (Agnew et al. 1998, Everson et al.1999). Such switching would be expected to result in the data points in Fig. 2 being concentrated at the extremes, whereas this is not the case. Clearly, the relationship between the rate of occurrence of prey in predator diets and their abundance in the environment is a fundamental characteristic of the predatorprey interaction. This relationship could take various forms, which are determined by factors such as the spatial distribution of prey and the behaviour of both predators and prey. However, the current state of knowledge for the species considered in this paper is not sufficient to determine this relationship, and the

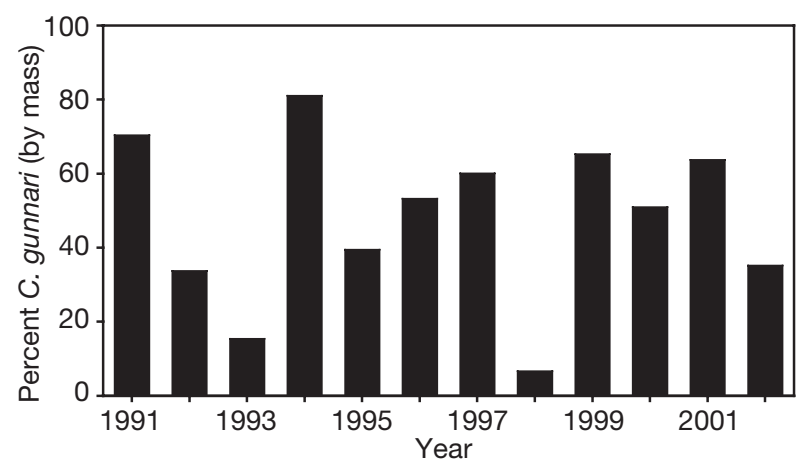

Fig. 1. Champsocephalus gunnari. Contribution by mass of mackerel icefish to the diet of gentoo penguins during the chick-rearing period at Bird Island from 1991 to 2002

most parsimonious model is a linear relationship between relative abundance and consumption rate (Hill et al. 2005).

\section{Predator consumption of mackerel icefish}

Based on historical data on the diet of gentoo penguins in which ca. $33 \%$ of the diet was considered to be fishes, of which ca. $30 \%$ comprised mackerel icefish, (Croxall et al. 1984), Everson et al. (1999) suggested that they might consume ca. $7500 \mathrm{t}$ of mackerel icefish $\mathrm{yr}^{-1}$ at South Georgia. However, based on the results presented herein, in which ca. $50 \%$ of the diet was fish, of which $90 \%$ comprised mackerel icefish, the level of consumption by gentoo penguins would be of the order of $38000 \mathrm{t} \mathrm{yr}^{-1}$. This amount exceeds the estimate for the standing stock at South Georgia in 4 of the 7 yr considered by Everson et al. (1999), suggesting some combination of an overestimate of consumption and/or an underestimate of the standing-stock size. That this consumption level represents only consump-

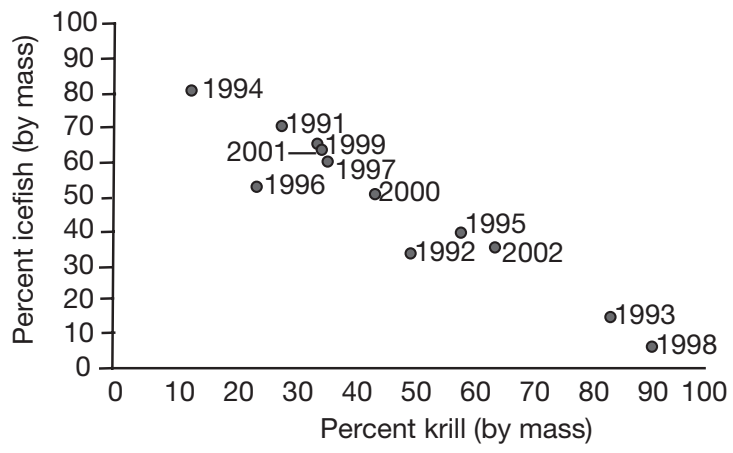

Fig. 2. Champsocephalus gunnari and Euphausia superba. Relative contribution by mass of mackerel icefish and Antarctic krill to the diet of gentoo penguins during the chickrearing period at Bird Island from 1991 to 2002 


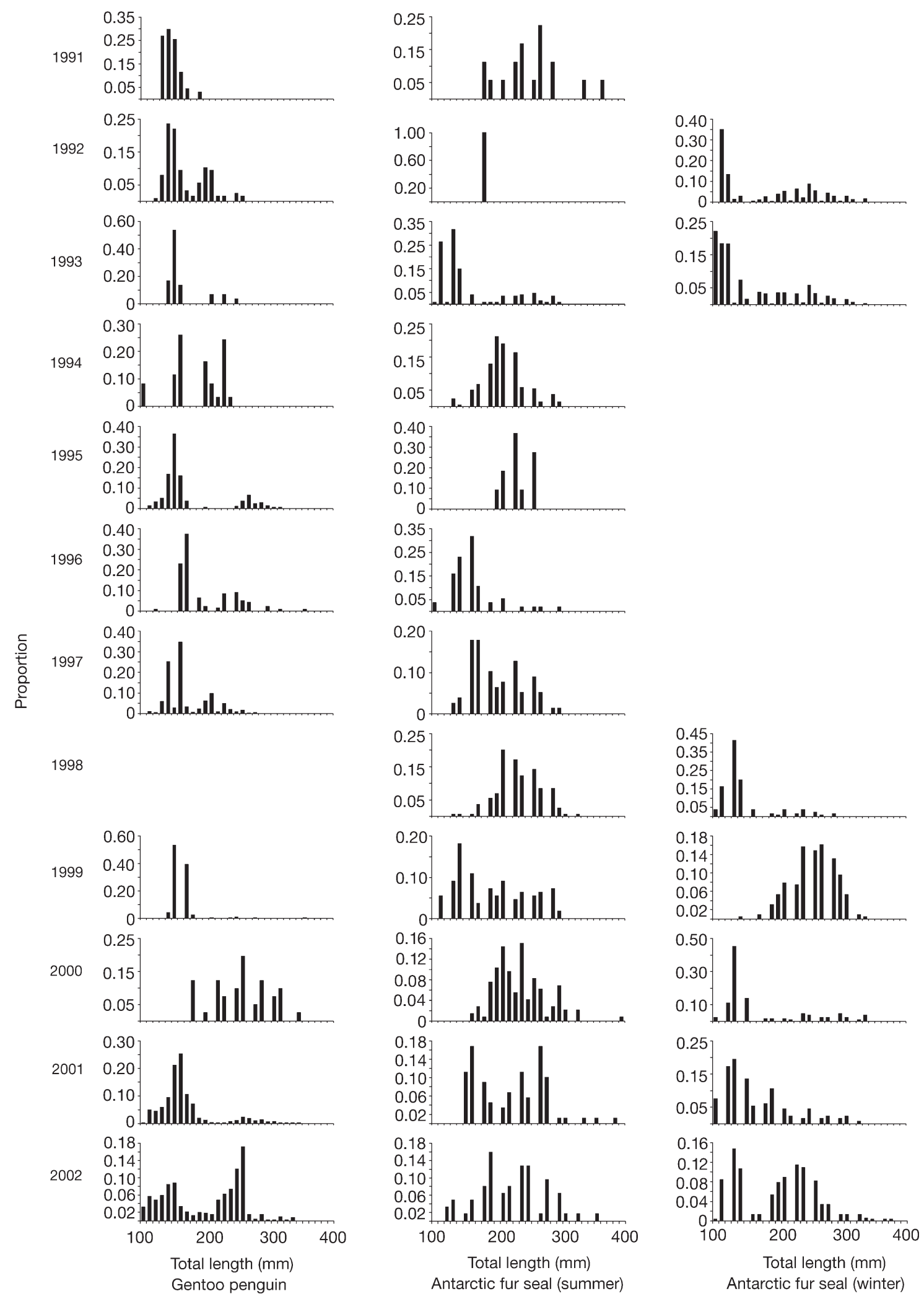

Fig. 3. Champsocephalus gunnari. Length-frequency distribution of mackerel icefish in the diets of Antarctic fur seals during winter and summer and gentoo penguins during the chick-rearing period at Bird Island from 1991 to 2002. Graphs for Antarctic fur seals are aligned to show the winter following the relevant summer, e.g. for 2002 the 2 fur seal columns cover period October 2001 to March 2002 (summer) and April 2002 to November 2002 (winter) 
tion by gentoo penguins and excludes that of other predators, including Antarctic fur seals (which are 1 order of magnitude larger and 2 orders of magnitude more numerous and may therefore be expected to consume more mackerel icefish) makes the mismatch more evident.

Because of methodological differences and the lack of quantitative information on the diet of fur seals, it is not possible using the current data to compare the contribution by mass of mackerel icefish to the diet of Antarctic fur seals with that of gentoo penguins. However, it is clear that mackerel icefish comprise an important part of the diet of Antarctic fur seals in summer, and more especially in winter. While the derivation of quantitative estimates of consumption from qualitative (frequency of occurrence) data must be applied with caution, even the most conservative estimates of the consumption by Antarctic fur seals indicate their potential to have a considerable impact on the local population of mackerel icefish. Boyd (2002) estimated that the annual food consumption by Antarctic fur seals at South Georgia was of the order of 3.84 million $t$, assuming a diet of $90 \% \mathrm{krill}$ and $10 \%$ fish. The mackerel icefish is one of the 3 most frequently occurring fish species in the diet of Antarctic fur seals, the others being Lepidonotothen larseni and Protomyctophum choriodon (Reid 1995, Reid \& Arnould 1996). Therefore, if mackerel icefish contribute at least one-third to the fish component of the diet (which may well be a conservative estimate) this would result in an estimated annual consumption of the order of 100000 t. Despite considerable numerical and structural uncertainty associated with the estimation of consumption, the combined value for Antarctic fur seals and gentoo penguins (138000 $\mathrm{t} \mathrm{yr}^{-1}$ ) compared to the current estimated standing-stock size does not seem plausible. In order to fully address these uncertainties and provide confidence intervals for the predator consumption estimates, additional sampling is required together with analytical approaches that can provide quantitative information with which to parameterise energetics and life-history models that include all species concerned in the major trophic interactions involving mackerel icefish.

A potential bias in the estimates of consumption by predators is the extent to which the consumption levels and population structure of mackerel icefish in the diet of predators at Bird Island can be extrapolated to all waters surrounding South Georgia. Antarctic fur seals and gentoo penguins are present year-round on Bird Island. In the case of Antarctic fur seals, females are numerically dominant in the summer with males dominating in the winter (Duck 1990, Reid 1995). The foraging distribution of female fur seals rearing pups on Bird Island during the summer is concentrated in the
NW of South Georgia (Boyd et al. 2002), whilst recently collected data suggest that the foraging of males during winter covers a wider area, but is generally concentrated over the shelf and shelf-break (British Antarctic Survey unpubl. data). Gentoo penguins make daily foraging trips during the chick-rearing period, and their foraging is restricted to less than $20 \mathrm{~km}$ from land (Williams et al. 1992, Bevan et al. 2002, Tanton et al. 2004). Hence, samples of predator diets from Bird Island are only likely to be representative of the shelf-region NW of South Georgia. There are no data on the diet of Antarctic fur seals or gentoo penguins from elsewhere around South Georgia, although such data could readily be obtained for fur seals, as scat collection and processing is relatively simple and does not require animal capture.

The majority of the foraging dives of Antarctic fur seal are within the top $50 \mathrm{~m}$ (Boyd et al. 1994), whereas the survey samples were collected using a bottom trawl, at a mean depth of around $250 \mathrm{~m}$. This difference in the sections of the water column sampled by research surveys and predators also highlights a potential bias that might lead to an underestimate of the standing stock derived from bottom-trawl surveys. Evidence of age-specific depth stratification in the population suggests that a substantial component of the mackerel icefish population, particularly the younger age classes which dominate in the diet of predators, may not be sampled effectively by bottom trawls (Frolkina 2002, Collins et al. 2004).

\section{Population dynamics of mackerel icefish indicated by predator-derived data}

In presenting developments towards the management of mackerel icefish, Agnew et al. (1998) highlighted the importance of using data from predators to indicate levels of consumption. On the basis of the consumption levels described herein, estimates of predator-derived mortality may well be an important consideration in the population dynamics of mackerel icefish. However, Agnew et al. (1998) did not consider the potential for collecting data on the size-structure of the population from measurements of the otoliths in the diet of predators. Whilst there are undoubtedly biases associated with using information from the diet of predators, the data presented herein indicate patterns of recruitment variability of the 1+ age class (130 to $180 \mathrm{~mm}$ total length), indicated by the presence/absence of this age class in the diet of both Antarctic fur seals and gentoo penguins over an extended period including summer and winter. It is also possible to follow the progression of cohorts through the population for $2 \mathrm{yr}$, after which the onto- 
genic shift in depth described by Frolkina (2002) and Collins et al. (2004) is likely to restrict the level of overlap in the foraging depths of predators and the older/larger prey fish. The ability to track cohorts in this way suggests that this approach has the potential to provide useful information on population processes in mackerel icefish, as already demonstrated for Antarctic krill in the diets of predators, including Antarctic fur seals (Reid et al. 1999, Murphy \& Reid 2001, Fraser \& Hofmann 2003).

During the time-series covered by in this study, strong $1+$ cohorts, which arose from spawning $2 \mathrm{yr}$ earlier, appeared to enter the population in 1993, 1996, 1999 and 2001 (Fig. 3). There is much evidence of environmental influences on recruitment variability in marine organisms (Mann 1993, Myers 1998, Fraser \& Hofmann 2003), and the ability to relate environmental conditions, either in the year of spawning or during the early-life history stages, to the level of recruitment $2 \mathrm{yr}$ hence would be of considerable value in stock projections. However, further work is required to determine these relationships for icefish (Everson et al. 2000, Everson \& Kock 2001, but see Hill et al. 2005).

\section{Implications for fisheries management}

Agnew et al. (1998) and Everson et al. (1999) hypothesised that the large interannual variability in trawlsurvey estimates of mackerel icefish could be attributed to episodes of high mortality associated with increased consumption by predators during periods of low krill availability. The results of the current study indicate that while there was some evidence of increased predator consumption during 1994, this was not the case in 1991 (at least in the case of Antarctic fur seals) despite unusually low krill abundance in both years (data in Reid et al. 2005). In addition there were periods when increases in the prevalence of mackerel icefish (i.e. the number of otoliths per scat) were not associated with low krill abundance.

It is clear from the positive relationship between krill abundance and the amount of krill in the diet of gentoo penguins (Reid et al. 2005), and the relationship found in this study between the relative proportions of icefish and krill in their diet, that there is a relationship between krill abundance and the consumption of mackerel icefish. However, since some periods of increased consumption of icefish were not associated with low krill abundance, this suggests that there is also some intrinsic component of the variability in the abundance of icefish that influences its occurrence in the diet of predators.

The results of this study confirm that mackerel icefish are an important component of the diet of both
Antarctic fur seals and gentoo penguins at South Georgia, species that are generally considered to be krilldependent predators (Croxall et al. 1997). Conservative estimates of consumption of mackerel icefish by these 2 species are in excess of current stock-size estimates. However, a clearer understanding of the errors associated with both the consumption and stock-size estimates and the age/size structure of icefish consumed by predators and taken by the fishery is required to better interpret the ecological interactions involved. The apparent reduction in krill abundance at South Georgia in the 1990s compared to the 1980s (Reid \& Croxall 2001, Atkinson et al. 2004) and the continued increase in the fur seal population at South Georgia (Boyd 1993) may have brought about an overall increase in the mortality rate of mackerel icefish as a result of increased predator consumption. If this is the case, then it provides a potential explanation for the lack of a return to pre-exploitation population size after a major reduction in fishing effort. This highlights the need to consider the ecological relationships of exploited species and how these relationships change over time in response to changes in the host ecosystems, including those changes brought about by previous harvesting regimes.

Acknowledgements. We thank all of the many members of BAS staff who have collected and analysed diet samples at Bird Island, and Drs. I. Everson, M. Belchier and A. W. North, Members of the CCAMLR Working Group on Fish Stock Assessment, and 3 anonymous referees for helpful advice and discussion. This paper is part of the BAS core-funded DYNAMOE science programme.

\section{LITERATURE CITED}

Agnew DJ, Everson I, Kirkwood GP, Parkes G (1998) Towards the development of a management plan for the mackerel icefish Champsocephalus gunnari in subarea 48.3. CCAMLR Sci 5:63-77

Atkinson A, Siegel V, Pakhomov E, Rothery P (2004) Longterm decline in krill stock and increases in salps within the Southern Ocean. Nature 432:100-103

Bevan RM, Butler PJ, Woakes AJ, Boyd IL (2002) The energetics of gentoo penguins Pygoscelis papua during the breeding season. Funct Ecol 16:175-190

Boyd IL (1993) Pup production and distribution of breeding Antarctic fur seals Arctocephalus gazella at South Georgia. Antarct Sci 5:17-24

Boyd IL (2002) Estimating food consumption of marine predators: Antarctic fur seals and macaroni penguins. J Appl Ecol 39:103-119

Boyd IL, Arnould JPY, Barton T, Croxall JP (1994) Foraging behaviour of Antarctic fur seals during periods of contrasting prey abundance. J Anim Ecol 63:703-713

Boyd IL, Staniland IJ, Martin AR (2002) Distribution of foraging by female Antarctic fur seals. Mar Ecol Prog Ser 242:285-294

CCAMLR (Commission for Conservation of Marine Living Resources) (1995) CEMP standard methods. CCAMLR, Hobart 
Collins MA, Xavier JCC, Reid K, Belchier M, Goss C, Agnew DJ (2004) Does the current South Georgia Groundfish Survey accurately estimate the standing stock of mackerel icefish? CCAMLR WG-FSA-SAM 04/20. CCAMLR (Commission for Conservation of Marine Living Resources), Hobart

Constable AJ, de la Mare WK, Agnew DJ, Everson I, Miller D (2000) Managing fisheries to conserve the Antarctic marine ecosystem: practical implementation of the Convention on the Conservation of Antarctic Marine Living Resources (CCAMLR). ICES J Mar Sci 57:778-791

Croxall JP, Ricketts C, Prince PA (1984) Impact of seabirds on marine resources especially krill of South Georgia waters. In: Wittow GC, Rahn H (eds) Seabird energetics. Plenum, New York

Croxall JP, Prince PA, Reid K (1997) Dietary segregation of krill-eating South Georgia seabirds. J Zool 242:531-556

Duck CD (1990) Annual variation in the timing of reproduction in Antarctic fur seals Arctocephalus gazella at Bird Island South Georgia. J Zool 222:103-116

Everson I, Kock KH (2001) Variations in condition indices of mackerel icefish at South Georgia from 1972 to 1997 CCAMLR Sci 8:119-132

Everson I, Parkes G, Kock KH, Boyd IL (1999) Variation in standing stock of the mackerel icefish Champsocephalus gunnari at South Georgia. J Appl Ecol 36:591-603

Everson I, Kock KH, Ellison J (2000) Inter-annual variation in the gonad cycle of the mackerel icefish J Fish Biol 57: 103-111

Fraser WR, Hofmann EE (2003) A predator's perspective on causal links between climate change, physical forcing and ecosystem response. Mar Ecol Prog Ser 265:1-15

Frolkina ZA (2002) Distribution of mackerel icefish Champsocephalus gunnari Channichthyidae around South Georgia at various stages of the life cycle. CCAMLR Sci 9:49-70

Gislason H, Sinclair M, Sainsbury K, O'Boyle R (2000) Symposium overview: incorporating ecosystem objectives within fisheries management. ICES J Mar Sci 57:468-475

Hecht T (1987) A guide to the otoliths of Southern Ocean fishes. S Afr J Antarct Res 17:1-87

Hill SL, Reid K, North AW (2005) Recruitment of mackerel icefish at South Georgia indicated by the analysis of predator diets and its relationship with sea surface temperature. Can J Fish Aquat Sci 62:2530-2537

Kock KH (1992) Antarctic fish and fisheries. Cambridge University Press, Cambridge

Kock KH, Everson I (1997) Biology and ecology of mackerel icefish Champsocephalus gunnari: an Antarctic fish lacking haemoglobin. Comp Biochem Physiol A 118: 1067-1077

Mangel M, Talbot LM, Meffe GK, Agardy MT and 38 others (1996) Principles for the conservation of wild living resources. Ecol Appl 6:338-362

Mann KH (1993) Physical oceanography food chains and fish stocks: a review. ICES J Mar Sci 50:105-119

Murphy EJ, Reid K (2001) Modelling Southern Ocean krill population dynamics: biological processes generating

Editorial responsibility: Otto Kinne (Editor-in-Chief), Oldendorf/Luhe, Germany fluctuations in the South Georgia ecosystem. Mar Ecol Prog Ser 217:175-189

Myers RA (1998) When do environment-recruitment correlations work? Rev Fish Biol Fish 8:285-305

Olsson O, North AW (1997) Diet of the king penguin Aptenodytes patagonicus during three summers at South Georgia. Ibis 139:504-512

Pikitch EK, Santora C, Babcock EA, Bakun A and 13 others (2004) Ecosystem-based fishery management. Science 305:346-347

Pilling GM, Purves MG, Daw TM, Agnew DA, Xavier JC (2001) The stomach contents of Patagonian toothfish around South Georgia (South Atlantic). J Fish Biol 59:1370-1384

Reid K (1995) The diet of Antarctic fur seals Arctocephalus gazella Peters, 1875 during winter at South Georgia. Antarct Sci 7:241-249

Reid K (1996) A guide to the use of otoliths in the study of predators at South Georgia. British Antarctic Survey, Cambridge

Reid K, Arnould JPY (1996) The diet of Antarctic fur seals Arctocephalus gazella during the breeding season at South Georgia. Polar Biol 16:105-114

Reid K, Croxall JP (2001) Environmental response of upper trophic-level predators reveals a system change in an Antarctic marine ecosystem. Proc R Soc Lond B Ser 268: 377:384

Reid K, Croxall JP, Prince P (1996) The fish diet of blackbrowed albatross Diomedia melanophris and grey-headed albatross D. chrysostoma at South Georgia. Polar Biol 16: 469-477

Reid K, Watkins J, Croxall JP, Murphy EJ (1999) Krill population dynamics at South Georgia 1991-1997 based on data from predators and nets. Mar Ecol Prog Ser 117:103-114

Reid K, Croxall JP, Briggs DR, Murphy EJ (2005) Antarctic ecosystem monitoring: quantifying the response of ecosystem indicators to variability in Antarctic krill. ICES J Mar Sci 62:366-373

Tanton JL, Reid K, Croxall JP, Trathan PN (2004) Winter distribution and behaviour of gentoo penguins Pygoscelis papua at South Georgia. Polar Biol 27:299-303

Williams R, McEldowney A (1990) A guide to the fish otoliths from waters off the Australian Antarctic Territory, Heard and Macquarie Island. ANARE (Aust Natl Antarct Res Exped) Res Notes No. 75

Williams TD (1990) Foraging ecology and diet of gentoo penguins Pygoscelis papua at South Georgia during winter and an assessment of their winter prey consumption. Ibis 133:3-13

Williams TD, Briggs DR, Croxall JP, Naito Y, Kato A (1992) Diving pattern and performance in relation to foraging ecology in the gentoo penguin Pygoscelis papua. J Zool 227 211-230

Wilson RP (1984) An improved stomach pump for penguins and other seabirds. J Field Ornithol 55:109-112

Xavier JC, Croxall JP, Reid K (2003) Interannual variation in the diets of two albatross species breeding at South Georgia: implications for breeding performance. Ibis 154: 593-610

Submitted: November 29, 2004; Accepted: June 28, 2005 Proofs received from author(s): December 2, 2005 